\title{
Application of FTIR-ATR spectroscopy and chemometrics for the detection and quantification of lard oil in bovine milk fat
}

\author{
${ }^{1}$ Windarsih, A., ${ }^{2,3}$ Irnawati and ${ }^{2,4,}{ }^{*}$ Rohman, A. \\ ${ }^{1}$ Research Division for Natural Product Technology (BPTBA), Indonesian Institute of Sciences (LIPI), \\ Yogyakarta, Indonesia, 55861 \\ ${ }^{2}$ Department of Pharmaceutical Chemistry, Faculty of Pharmacy, Universitas Gadjah Mada, Yogyakarta, \\ Indonesia, 55281 \\ ${ }^{3}$ Faculty of Pharmacy, Halu Oleo University, Kendari, Indonesia, 93232 \\ ${ }^{4}$ Institute of Halal Industry and System (IHIS), Universitas Gadjah Mada, Yogyakarta, Indonesia, 55281
}

\section{Article history: \\ Received: 26 February 2020 \\ Received in revised form: 29 \\ March 2020 \\ Accepted: 1 April 2020 \\ Available Online: 28 June 2020}

\section{Keywords:}

Bovine milk fat,

Discriminant analysis,

FTIR spectra,

Lard oil,

Partial least square

DOI:

https://doi.org/10.26656/fr.2017.4(5).087

\begin{abstract}
Bovine milk fat (BMF) is considered as high nutritional fat because it contains fatty acids, lipid derivatives, and fat-soluble vitamins such as vitamin $\mathrm{A}, \mathrm{D}, \mathrm{E}$, and $\mathrm{K}$ which are beneficial for human health. As a consequence, the price of BMF is higher among other fats. Fraudulent practices such as substitution or replacement with a lower price of fat and oil such as lard oil (LO) are potential to get more economic benefits. Moreover, lard is a non-halal substance which is prohibited to consume especially for Muslim. Therefore, the development of a rapid and accurate method for authentication of BMF from LO is highly required. The objective of this study was to develop Fourier transform infrared (FTIR) spectroscopy and chemometrics of multivariate analysis for detection and quantification of LO in binary mixtures with BMF. Samples were prepared by mixing BMF with adulterant of LO in the concentration range of $0-100 \%$ of LO. Each sample was scanned using FTIR attenuated total reflectance (ATR) spectroscopy in three replicates at the wavenumber region of 4000-650 $\mathrm{cm}^{-1}$. The FTIR spectra of BMF and LO has a different pattern at the wavenumber region of $1510-900 \mathrm{~cm}^{-1}$. Qualitative chemometrics analysis was performed using discriminant analysis (DA), meanwhile, quantitative chemometrics analysis was carried out using partial least square (PLS) and principal component regression (PCR). Results showed that discriminant analysis using normal FTIR spectra at the wavenumber of 3098-669 $\mathrm{cm}^{-1}$ perfectly classified authentic BMF and adulterated BMF with LO. In addition, PLS calibration of FTIR spectra at the wavenumber combination of 3033-2770 $\mathrm{cm}^{-1}$ and 1510-692 $\mathrm{cm}^{-1}$ using first derivative spectra was chosen for quantification of LO in BMF with a high value of $\mathrm{R}^{2}(>0.99)$ in calibration and validation models and lower RMSEC (0.631) and RMSEP (1.94). It can be concluded that FTIR spectroscopy coupled with chemometrics of discriminant analysis and partial least square considered as a rapid and accurate method for the detection and quantification of lard oil in bovine milk fat.
\end{abstract}

\section{Introduction}

Milk fat is one of the milk-derived products that play an important role in nutrition because it has essential fatty acid and fat-soluble vitamins (Azad and Ahmed, 2016). There are several types of milk fat including bovine milk fat (BMF) which has been widely used in many dairy and food products. It also contains triglycerides, proteins, lactose, minerals, and fat-soluble vitamins such as vitamin $\mathrm{A}, \mathrm{D}, \mathrm{E}$, and $\mathrm{K}$ which are good for body health (Miciński et al., 2012; Yao et al., 2016). Among types of fats, BMF is considered as the most valuable and expensive fat in the market. Due to increased demand, fraudulent practice such as adulteration of BMF by replacing with other lower price and quality of fats or oils is very potential to get more economic benefits. Animal fats and vegetable oils are cheaper and easy to be mixed directly with BMF (Rebechi et al., 2016). Incorporating lard oil (LO) in milk fat would become a serious problem especially for Muslim because it is categorized as a non-halal substance and Muslim are prohibited to consume products containing the non-halal substance (Che Man and Mirghani, 2001; Che Man and Rohman, 2011). 
Lard oil (LO) contains more unsaturated fats and lower cholesterol which has been widely used as important ingredients in several countries. LO has broad applications in food processing because it has good characteristics and suitable for any kinds of food (Yanty et al., 2012; Pavlisova et al., 2016; Azir et al., 2017). Moreover, it has good properties that make it easy to be mixed with other types of fats and oils. Even though it just been added in a very few amounts of concentration levels, the consumption of LO is prohibited for Muslim because LO is categorized as non-halal substance (Aziz et al., 2015). The presence of non-halal substances is not allowed in any kind of labelled halal food. Therefore, the development of rapid and reliable analytical methods for authentication of BMF from LO is highly required to ensure the quality and halal status of BMF products.

Several methods especially chromatographic methods have been developed for authentication of milk fat including gas chromatography (GC) (Amores and Virto, 2019) and high performance liquid chromatography (HPLC) (Czauderna et al., 2002; Gastaldi et al., 2011). GC has been applied for the detection of pork lard and beef tallow in milk fat by determining the fatty acid composition. The fatty acid of oleic acid could be used as marker fatty acid (Kim et al., 2016). HPLC has been used for the analysis of triglyceride in milk fat. The composition of triglyceride is very useful for differentiation of authentic and adulterated milk fat (Naviglio et al., 2017). However, chromatography methods are destructive, are laborious, requiring more time, and requiring many chemical solvents. As a consequence, these methods are not suitable for rapid screening method and for routine analysis in the laboratory. Therefore, the development of rapid and non-destructive method such as infrared spectroscopy, UV-Vis spectroscopy, and Raman spectroscopy are potential to be developed as nondestructive and fast analysis for BMF authentication (Lee et al., 2018; He et al., 2019).

Fourier transform infrared (FTIR) spectroscopy is gaining more attractions as an ideal method for rapid authentication analysis. Moreover, in combination with chemometrics of multivariate analysis, FTIR using ATR (attenuated total reflectance) mode offers rapid and reliable methods, fast analysis, simple in sample preparation, require minimum solvent (green analytical chemistry) (Moros et al., 2010), reproducible and could be applied for a wide range of samples (Li et al., 2019). FTIR spectroscopy and chemometrics have been widely employed for authentication of oils and fats (Worley and Powers, 2013). FTIR-ATR spectroscopy in combination with chemometrics of pattern recognition discriminant analysis (DA) and multivariate calibration partial least square (PLS) and principal component regression (PCR) has been used for authentication of extra virgin olive oil from its potential adulterants (grapeseed, soybean, and walnut oils) (Lerma-García et al., 2010). Combination of FTIR spectroscopy and PLS has also been successfully used for the detection and quantification of palm oil and canola oil in avocado oil (Rohman et al., 2016). FTIRATR and chemometrics have been used for detection of goat body fat in pure ghee (Upadhyay et al., 2016). Based on the literature study, there is no report about the employment of FTIR-ATR spectroscopy and chemometrics for authentication of bovine milk fat (BMF) adulterated with lard oil (LO). The objective of this study was to develop FTIR-ATR spectroscopy method coupled with chemometrics of discriminant analysis (DA), partial least square (PLS), and principal component regression (PCR) for authentication of bovine milk fat (BMF) from lard oil (LO) as an adulterant.

\section{Materials and methods}

\subsection{Materials}

Bovine milk fat (BMF) and lard oil (LO) were purchased from a local market in Yogyakarta, Indonesia. The solvents used for FTIR measurements (n-hexane and acetone) were analytical grade and purchased from Merck.

\subsection{Sample preparation}

Samples preparation were carried out by mixing bovine milk fat (BMF) and adulterant of lard oil (LO) using adulterant concentration of $0-100 \% \mathrm{w} / \mathrm{w}$. The total weight of the mixture was $2 \mathrm{~g}$ for each sample.

\subsection{FTIR spectra measurement}

All samples were measured using FTIR-ATR (Fourier transform infrared-attenuated total reflectance) Thermo Scientific iS10 equipped with DTGS (deuterated triglycine sulphate) detector and $\mathrm{KBr} / \mathrm{Germanium}$ beam splitter. The ATR was composed of $\mathrm{ZnSe}$ crystal. Samples were scanned at the wavenumber of 4000-650 $\mathrm{cm}^{-1}$. The number of scans was 32 for each sample measurement and the resolution was $8 \mathrm{~cm}^{-1}$. Each sample was measured in three replicates as absorbance mode to suit Lambert-Beer law. Background spectra were measured before each sample measurement. The ATR crystal was cleaned using n-hexane and acetone after each measurement.

\subsection{FTIR spectra analysis}

The FTIR spectra of BMF and LO were analyzed using OMNIC software from Thermo. Peaks identification were carried out to investigate functional groups in the FTIR spectra of BMF and LO. The 
difference in FTIR spectra of BMF and LO was subsequently analyzed.

\subsection{Classification of authentic and adulterated bovine milk fat using discriminant analysis (DA)}

Supervised pattern recognition of discriminant analysis was used for classification analysis. Authentic BMF samples and adulterated BMF with LO were used as the training set for making a discriminant analysis model. The adulterated BMF samples were prepared using LO concentration of $0-100 \mathrm{w} / \mathrm{w}$. The authentic samples of BMF were assigned as BMF whereas the adulterated samples of BMF with $\mathrm{LO}$ were assigned as BMF adulterated with LO. Optimization of wavenumber region was performed to obtain good separation of BMF and adulterated BMF.

\subsection{Quantitative analysis of lard oil in bovine milk fat using multivariate calibration}

For making calibration samples, a set of 42 samples including authentic BMF, authentic LO, and adulterated $\mathrm{BMF}$ with $\mathrm{LO}$ in the concentration range of $0-100 \% \mathrm{w} / \mathrm{w}$ were prepared. Nine independent samples were prepared for making the validation model. Each mixture of samples was mixed vigorously to obtain homogenized samples. Quantitative analysis was carried out using partial least square (PLS) and principal component regression (PCR) in optimized wavenumber.

\subsection{Statistical analysis}

Chemometrics of discriminant analysis (DA), partial least square (PLS), and principal component regression (PCR) was carried out using TQ Analyst software by Thermo Scientific. Optimization of wavenumber was carried out in the range of $4000-650 \mathrm{~cm}^{-1}$.

\section{Results and discussion}

\subsection{FTIR spectra analysis}

FTIR spectroscopy has some advantages because of its fingerprint technique. It means that there are no samples having identical FTIR spectra because each sample is composed of different compounds. First, general investigation through our naked eyes showed that FTIR spectra of authentic BMF and authentic LO were very similar. However, a deep investigation between FTIR spectra of authentic BMF and authentic LO found some differences especially in the fingerprint region of $1500-750 \mathrm{~cm}^{-1}$ (Figure 1). Peaks appeared at $1413 \mathrm{~cm}^{-1}, 1238 \mathrm{~cm}^{-1}$ and $961 \mathrm{~cm}^{-1}$ were specific for BMF spectra, therefore they can be used as marker peaks for BMF spectra. These peaks correspond to the bending vibration (scissoring, twisting, and wagging) of $-\mathrm{CH}_{3}$ and $-\mathrm{CH}_{2}$ groups (Matwijczuk et al., 2019). The differences of fatty acid compositions in BMF and LO either in types or in length affected the FTIR spectra pattern. The functional groups identified in BMF and LO spectra were presented in Table 1. Even though FTIR spectra of authentic BMF and authentic LO could be differentiated, however in the adulterated samples of BMF with LO it would be difficult to be directly recognized because the spectra of adulterated samples were similar to those spectra of authentic BMF (Figure 2). Slight changes were identified in several wavenumber regions as adulterant concentration increased. It might be caused by the changes of compositions in BMF samples because of increasing LO concentration. However, it is very difficult to state whether the sample is authentic or

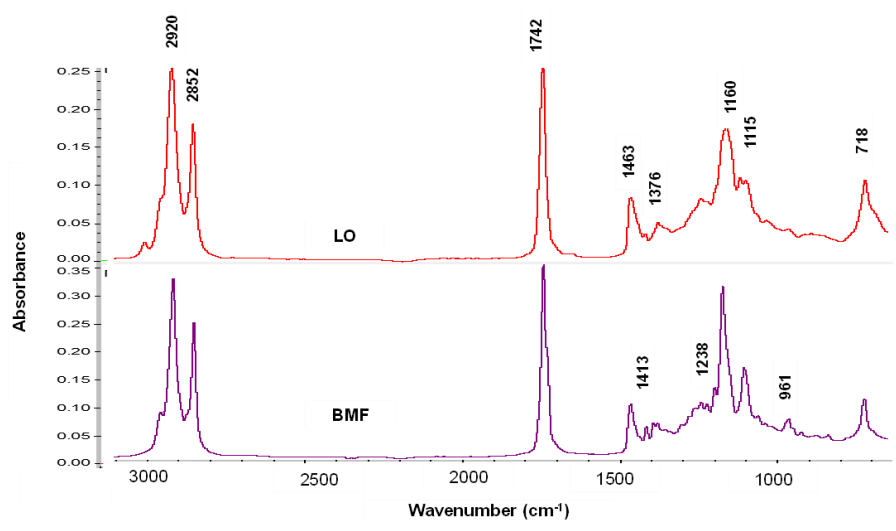

Figure 1. FTIR spectra of bovine milk fat (BMF) and lard oil (LO)

Table 1. Functional groups responsible for absorption of peaks and shoulders in bovine milk fat (BMF) and lard oil (LO) (Matwijczuk et al., 2019).

\begin{tabular}{cl}
\hline Wavenumbers region $\left(\mathrm{cm}^{-1}\right)$ & Functional groups and vibration modes \\
\hline 3007 & cis $\mathrm{C}=\mathrm{CH}$, stretching vibration \\
2920 and 2852 & methylene $\left(-\mathrm{CH}_{2}\right)$, asymmetric and symmetric stretching vibrations \\
1742 & carbonyl $(\mathrm{C}=\mathrm{O})$, stretching vibration \\
1654 & $\mathrm{C}=\mathrm{C}$, stretching vibration \\
1463 & methylene $\left(-\mathrm{CH}_{2}\right)$, bending vibration \\
$1413,1376,1238,1160$ & methyl $\left(-\mathrm{CH}_{3},-\mathrm{CH}_{2}\right)$ bending vibration (wagging, twisting, scissoring) \\
1115 & $\mathrm{C}-\mathrm{O}$, stretching vibrations \\
961 & $-\mathrm{HC}=\mathrm{CH}-($ trans $)$, bending out of plane \\
718 & $-\mathrm{HC}=\mathrm{CH}-($ cis $)$, bending out of plane \\
\hline
\end{tabular}


adulterated just by investigating the spectra when there is no information related to the samples. Therefore, multivariate analysis like discriminant analysis must be performed for further investigations.

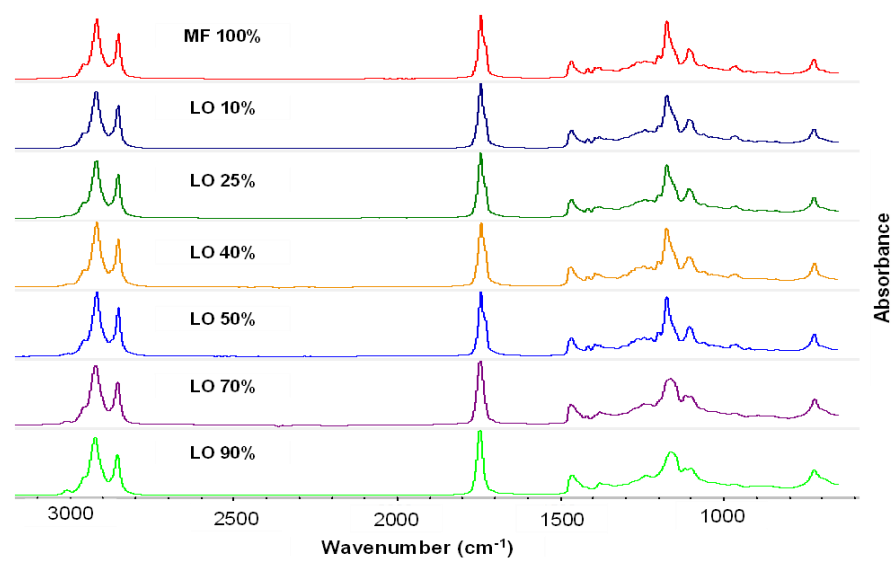

Figure 2. FTIR spectra of authentic BMF and adulterated BMF with $\mathrm{LO}$ in several concentration levels

\subsection{Discriminant analysis (DA)}

Discriminant analysis was used to classify authentic BMF and adulterated BMF with LO. DA perfectly work to differentiate authentic BMF fat with adulterated of BMF. All adulterated samples were clearly separated from authentic BMF even in lower adulterant concentration of $5 \%$ as shown in Cooman plot (Figure 3). Optimization of wavenumber was carried out to obtain complete separation between authentic and adulterated samples. The optimum condition was obtained in the wavenumber range of $3098-669 \mathrm{~cm}^{-1}$ using normal spectra. The $\mathrm{x}$-axis showed the Mahalanobis distance between two categorized samples. Samples which have a greater distance to BMF showed more differences to BMF. For instance, samples having the highest concentration of LO appeared far away from authentic BMF samples because there was an increase in differences of the compounds (Sohng et al., 2020).

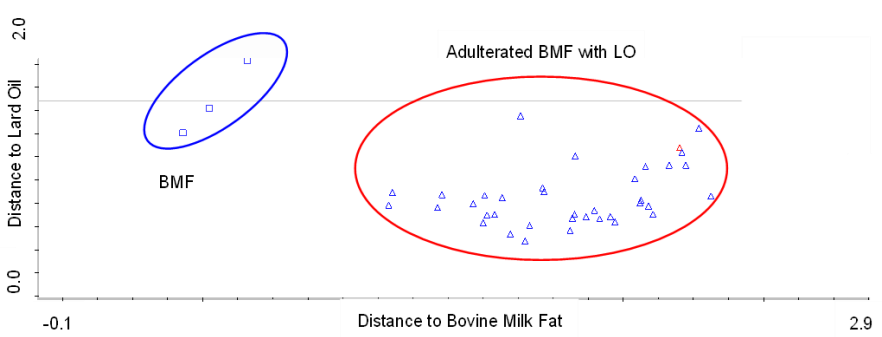

Figure 3. Discriminant analysis of authentic bovine milk fat (BMF) and adulterated BMF with lard oil (LO) in the wavenumber of $1510-692 \mathrm{~cm}^{-1}$.

\subsection{Multivariate calibration using partial least square (PLS) and principal component regression (PCR)}

Partial least square (PLS) and principal component regression (PCR) were used to build the calibration model for quantification of LO in BMF. Optimization of wavenumber region was carried out to obtain optimum calibration models, namely $1510-692 \mathrm{~cm}^{-1}, 1806-692 \mathrm{~cm}^{-}$ 1 , 3033-692 $\mathrm{cm}^{-1}$, combination of 3033-2077 and 1510$692 \mathrm{~cm}^{-1}$, and combination of 3033-2077 and 1808-692 $\mathrm{cm}^{-1}$. The spectra were also optimized using normal and derivative spectra. The aim of the derivatization method was to obtain better spectra resolution. Derivatization could resolve the crowded spectra to be easier to analyze (Nugrahani et al., 2019) Both of derivatization types were performed, namely first derivative and second derivative. Table 2 shows the optimization of the calibration model using PLS and PCR chemometrics method. The optimum model was chosen by assigning the value of $\mathrm{R}^{2}$ calibration and prediction, RMSEC (root mean square error of calibrations), and RMSEP (root mean square error of predictions).

The model with a higher value of $\mathrm{R}^{2}$ and a lower value of RMSEC and RMSEC was chosen as the calibration model. Higher $R^{2}$ value (close to 1 ) showed the validity and goodness of fit of the calibration model (Riyanta et al., 2020). RMSEC and RMSEP value indicated the error in calibration and prediction models, respectively. The lower values of RMSEC and RMSEP indicated a lower error in calibration and validation models, respectively (Worley and Powers, 2013). The PLS calibration model at the wavenumber combination of 3033-2770 $\mathrm{cm}^{-1}$ and 1510-692 $\mathrm{cm}^{-1}$ using first derivative spectra was selected as optimum calibration model for quantification of LO in binary mixtures with BMF because it has higher $\mathrm{R}^{2}$ calibration $(0.9998)$ and $\mathrm{R}^{2}$ prediction (0.9993) and lower RMSEC (0.631) and RMSEP values (1.94) among others. Moreover, the lower difference between RMSEC and RMSEP strongly support model validity.

PLS method showed better calibration models than the PCR method assigned by the value of $\mathrm{R}^{2}$, RMSEC, and RMSEP values as can be seen in Table 2. It might be caused by the difference in the algorithm of PLS and PCR method. In PLS regression, latent variables were used to build the calibration model to obtain maximum variation whereas, in the PCR method, the model was built using principal components (PCs). Hundreds of variables in PCR were transformed into several PCs that explain the variation of original variables. In some cases, latent variable gives better variation than PCs as a result it would make better calibration model of PLS than in PCR (Upadhyay et al., 2016). The PLS calibration model between actual value and the predicted value of $\mathrm{LO}$ in binary mixtures with BMF is shown in Figure 4A. The actual and predicted value of LO in BMF have strong correlation showed by $\mathrm{R}^{2}$ calibration $(0.9998)$. The linear regression was obtained either in calibration or validation models using the number of factors 10 . It 
Table 2. Multivariate calibration of PLS and PCR models of bovine milk fat adulterated with lard oil

\begin{tabular}{|c|c|c|c|c|c|c|}
\hline \multirow{3}{*}{$\begin{array}{c}\text { Calibration } \\
\text { Types }\end{array}$} & \multirow{3}{*}{ Wavenumber $\left(\mathrm{cm}^{-1}\right)$} & \multirow{3}{*}{ Spectra } & \multicolumn{4}{|c|}{ PLS } \\
\hline & & & \multicolumn{2}{|c|}{ Calibration } & \multicolumn{2}{|c|}{ Validation } \\
\hline & & & $\mathrm{R}^{2}$ & RMSEC & $\mathrm{R}^{2}$ & RMSEP \\
\hline \multirow{15}{*}{ PLS } & \multirow{3}{*}{$1510-692$} & Normal & 0.9060 & 14.60 & 0.9377 & 13.20 \\
\hline & & First derivative & 0.9994 & 1.24 & 0.9984 & 2.19 \\
\hline & & Second derivative & 0.9995 & 1.05 & 0.9986 & 2.30 \\
\hline & \multirow{3}{*}{$1806-692$} & Normal & 0.8929 & 15.60 & 0.9206 & 14.60 \\
\hline & & First derivative & 0.9992 & 1.39 & 0.9987 & 1.96 \\
\hline & & Second derivative & 0.9996 & 1.00 & 0.9991 & 1.51 \\
\hline & \multirow{3}{*}{$3033-692$} & Normal & 0.9923 & 4.28 & 0.9926 & 4.55 \\
\hline & & First derivative & 0.9947 & 3.55 & 0.9921 & 4.63 \\
\hline & & Second derivative & 0.9999 & 0.38 & 0.9982 & 2.12 \\
\hline & \multirow{3}{*}{$3033-2770$ and $1510-692$} & Normal & 0.9907 & 4.71 & 0.9931 & 4.52 \\
\hline & & First derivative & 0.9998 & 0.63 & 0.9993 & 1.94 \\
\hline & & Second derivative & 0.9998 & 0.75 & 0.9985 & 2.25 \\
\hline & \multirow{3}{*}{$3033-2770$ and $1806-692$} & Normal & 0.9833 & 6.30 & 0.9789 & 7.35 \\
\hline & & First derivative & 0.9994 & 1.20 & 0.9990 & 1.73 \\
\hline & & Second derivative & 0.9998 & 0.75 & 0.9993 & 1.50 \\
\hline \multirow{15}{*}{ PCR } & \multirow{3}{*}{$1510-692$} & Normal & 0.9983 & 2.02 & 0.9979 & 2.44 \\
\hline & & First derivative & 0.9989 & 1.60 & 0.9984 & 2.21 \\
\hline & & Second derivative & 0.9986 & 1.84 & 0.9965 & 3.14 \\
\hline & \multirow{3}{*}{$1806-692$} & Normal & 0.9984 & 1.96 & 0.9974 & 2.66 \\
\hline & & First derivative & 0.9979 & 2.24 & 0.9969 & 3.01 \\
\hline & & Second derivative & 0.9976 & 2.38 & 0.9946 & 3.83 \\
\hline & \multirow{3}{*}{$3033-692$} & Normal & 0.9979 & 2.22 & 0.9981 & 2.37 \\
\hline & & First derivative & 0.9978 & 2.30 & 0.9972 & 2.85 \\
\hline & & Second derivative & 0.9972 & 2.59 & 0.9911 & 4.81 \\
\hline & \multirow{3}{*}{$3033-2770$ and $1510-692$} & Normal & 0.9981 & 2.16 & 0.9990 & 1.78 \\
\hline & & First derivative & 0.9983 & 2.04 & 0.9977 & 2.73 \\
\hline & & Second derivative & 0.9981 & 2.14 & 0.9952 & 3.49 \\
\hline & \multirow{3}{*}{$3033-2770$ and $1806-692$} & Normal & 0.9982 & 2.06 & 0.9986 & 2.03 \\
\hline & & First derivative & 0.9975 & 2.43 & 0.9972 & 2.92 \\
\hline & & Second derivative & 0.9975 & 2.43 & 0.9947 & 3.67 \\
\hline
\end{tabular}

PLS = partial least square (multivariate calibration method based on latent variables); PCR = principal component regression (multivariate calibration based on principal components)

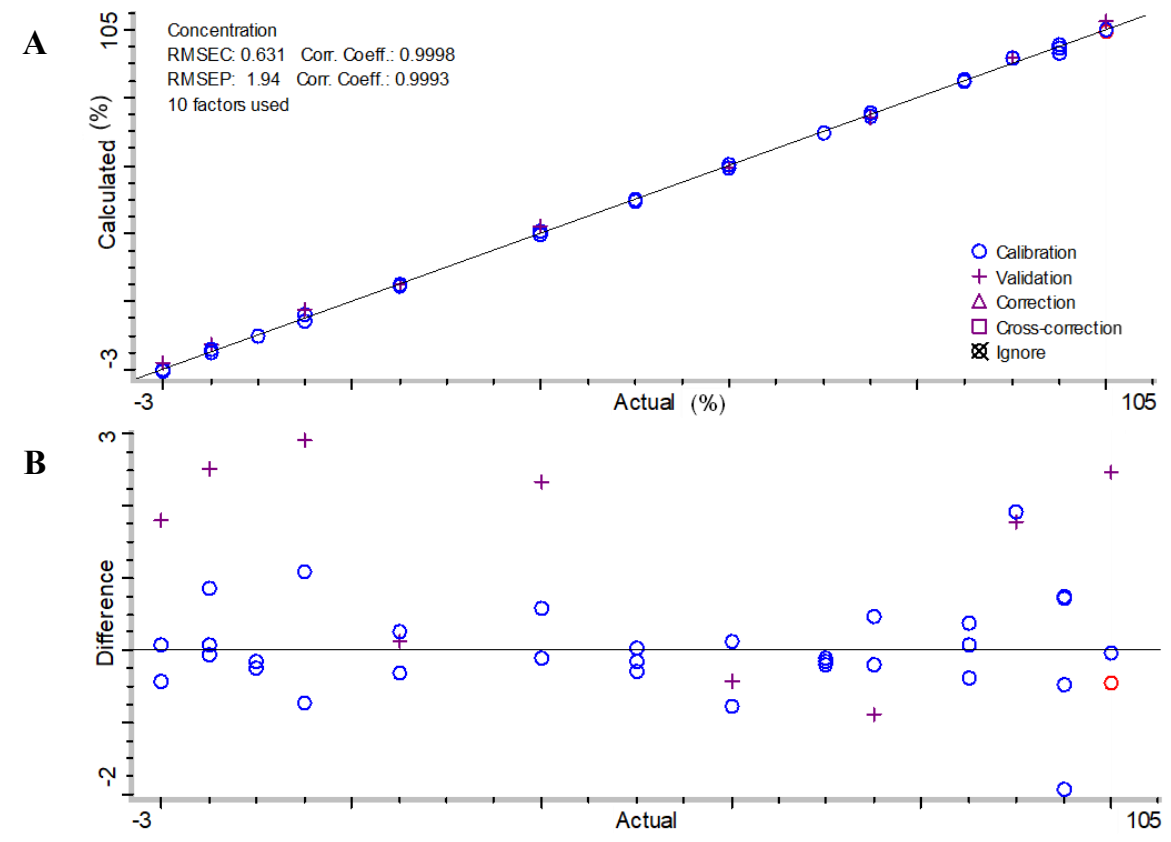

Figure 4. PLS calibration models (A) and residual factors (B) for quantification of LO in BMF. (Figure 4A: The $\mathrm{x}$-axis showed the actual concentration (\%) of LO in BMF, the y-axis showed the calculated concentration (\%) of LO in BMF by PLS method; Figure 4B: The $\mathrm{x}$-axis displayed the actual concentration (\%) of LO in BMF, the y-axis displayed the differences between actual and predicted concentration. The higher values of $\mathrm{R}^{2}$ calibration and $\mathrm{R}^{2}$ validation significantly affect the residual factors). 
means that the number of 10 factors were required to obtain lower PRESS value for making the calibration model. The smaller PRESS value, the better calibration model obtained. The residual factors of the PLS calibration model were determined to know the variation in the models (Figure 4B). Residual values indicated the differences between the actual and predicted value of LO. The smaller the difference between actual and predicted values, the better the calibration model was obtained. All of the calibration and validation samples displayed slight differences between actual and predicted values indicating the good of calibration and validation models. It can be concluded that good PLS calibration model resulted in small differences between actual and predicted concentration value.

\section{Conclusion}

The presence of lard oil (LO) in bovine milk fat (BMF) could be monitored using FTIR spectroscopy combined with chemometrics of multivariate analysis. Discriminant analysis (DA) worked perfectly for differentiation of authentic BMF and adulterated BMF with LO. All adulterated samples were clearly classified using the wavenumber region of 3098-669 $\mathrm{cm}^{-1}$. Quantitative analysis was successfully performed using chemometrics of partial least square (PLS) at the wavenumber combination of 3033-2770 and 1510-692 $\mathrm{cm}^{-1}$ in normal spectra mode. It can be concluded that the combination of FTIR spectroscopy and chemometrics of multivariate analysis is an adequate method for authentication of BMF adulterated with LO.

\section{Conflict of interest}

The authors declare there is no conflict of interest.

\section{Acknowledgement}

The authors thank Ministry of Research and Technology/National Agency for Research and Innovation Republic of Indonesia for financial support through Penelitian Dasar Unggulan Perguruan Tinggi 2020 with contract number 2729/UN1.DITLIT/DIT-LIT/ $\mathrm{PT} / 2020$, Indonesian Institute of Sciences (LIPI), Integrated Research and Testing and Laboratory (LPPT), and International Institute for Halal Research and Training (INHART) Malaysia for facilitating this research.

\section{References}

Amores, G. and Virto, M. (2019). Total and free fatty acids analysis in milk and dairy fat. Separations, 6 (1), $\quad 1-22$. $\quad$ https://doi.org/10.3390/ separations6010014
Azad, T. and Ahmed, S. (2016). Common milk adulteration and their detection techniques. International Journal of Food Contamination, 3(1), 1-22. https://doi.org/10.1186/s40550-016-0045-3

Azir, M., Abbasiliasi, S., Tengku Ibrahim, T., Manaf, Y., Sazili, A. and Mustafa, S. (2017). Detection of lard in cocoa butter-Its fatty acid composition, triacylglycerol profiles, and thermal characteristics. Foods, 6(11), 98-105. https://doi.org/10.3390/ foods6110098

Aziz, N.N.A., Abd.Aziz, N.A., Aziz, N.A.A., Omar, Z. and Hassan, W.H.A.W. (2015). A review on the emergence and growth of halal studies. Procedia Economics and Finance, 31, 325-332. https:// doi.org/10.1016/S2212-5671(15)01204-6

Che Man, Y.B. and Mirghani, M.E.S. (2001). Detection of lard mixed with body fats of chicken, lamb, and cow by Fourier Transform Infrared Spectroscopy. JAOCS, Journal of the American Oil Chemists' Society, 78(7), 753-761. https://doi.org/10.1007/ s11746-001-0338-4

Che Man, Y.B. and Rohman, A. (2011). Detection of lard in vegetable oils. Lipid Technology, 23(8), 180182. https://doi.org/10.1002/lite.201100128

Czauderna, M., Kowalczyk, J., Niedźwiedzka, K.M. and Wąsowska, I. (2002). A highly efficient method for derivatization of fatty acids for high performance liquid chromatography. Journal of Animal and Feed Sciences, 11(3), 517-526. https://doi.org/10.22358/ jafs/67905/2002

Gastaldi, D., Medana, C., Giancotti, V., Aigotti, R., Dal Bello, F. and Baiocchi, C. (2011). HPLC-APCI analysis of triacylglycerols in milk fat from different sources. European Journal of Lipid Science and Technology, 113(2), 197-207. https:// doi.org/10.1002/ejlt.201000068

He, H., Sun, D.W., Pu, H., Chen, L. and Lin, L. (2019). Applications of Raman spectroscopic techniques for quality and safety evaluation of milk: A review of recent developments. Critical Reviews in Food Science and Nutrition, 59(5), 770-793. https:// doi.org/10.1080/10408398.2018.1528436

Kim, H.J., Park, J.M., Lee, J.H. and Kim, J.M. (2016). Detection for non-milk fat in dairy product by gas chromatography. Korean Journal for Food Science of Animal Resources, 36(2), 206-214. https:// doi.org/10.5851/kosfa.2016.36.2.206

Lee, J.Y., Park, J.H., Mun, H., Shim, W.B., Lim, S.H. and Kim, M.G. (2018). Quantitative analysis of lard in animal fat mixture using visible Raman spectroscopy. Food Chemistry, 254, 109-114. https://doi.org/10.1016/j.foodchem.2018.01.185 
Lerma-García, M.J., Ramis-Ramos, G., HerreroMartínez, J.M. and Simó-Alfonso, E.F. (2010). Authentication of extra virgin olive oils by Fouriertransform infrared spectroscopy. Food Chemistry, 118(1), 78-83. https://doi.org/10.1016/ j.foodchem.2009.04.092

Li, Q., Chen, J., Huyan, Z., Kou, Y., Xu, L., Yu, X. and Gao, J.M. (2019). Application of Fourier transform infrared spectroscopy for the quality and safety analysis of fats and oils: A review. Critical Reviews in Food Science and Nutrition, 59(22), 3597-3611. https://doi.org/10.1080/10408398.2018.1500441

Matwijczuk, A., Oniszczuk, T., Matwijczuk, A., Chruściel, E., Kocira, A., Niemczynowicz, A., Wójtowicz, A., Combrzyński, M. and Wiacek, D. (2019). Use of FTIR spectroscopy and chemometrics with respect to storage conditions of Moldavian Dragonhead Oil. Sustainability (Switzerland), 11 (22), 1-16. https://doi.org/10.3390/su11226414

Miciński, J., Zwierzchowski, G., Kowalski, I.M., Szarek, J., Pierozyński, B. and Raistenskis, J. (2012). The effects of bovine milk fat on human health. Polish Annals of Medicine, 19(2), 170-175. https:// doi.org/10.1016/j.poamed.2012.07.004

Moros, J., Garrigues, S. and Guardia, M.D.L. (2010). Vibrational spectroscopy provides a green tool for multi-component analysis. TrAC Trends in Analytical Chemistry, 29(7), 578-591. https:// doi.org/10.1016/j.trac.2009.12.012

Naviglio, D., Dellagreca, M., Ruffo, F., Andolfi, A. and Gallo, M. (2017). Rapid analysis procedures for triglycerides and fatty acids as pentyl and phenethyl esters for the detection of butter adulteration using chromatographic techniques. Journal of Food Quality, 2017, $9698107 . \quad$ https:// doi.org/10.1155/2017/9698107

Nugrahani, I., Manosa, E.Y. and Chintya, L. (2019). FTIR-derivative as a green method for simultaneous content determination of caffeine, paracetamol, and acetosal in a tablet compared to HPLC. Vibrational Spectroscopy, 104, 102941. https://doi.org/10.1016/ j.vibspec.2019.102941

Pavlisova, J., Bardova, K., Stankova, B., Tvrzicka, E., Kopecky, J. and Rossmeisl, M. (2016). Corn oil versus lard: Metabolic effects of omega-3 fatty acids in mice fed obesogenic diets with different fatty acid composition. Biochimie, 124, 150-162. https:// doi.org/10.1016/j.biochi.2015.07.001

Rebechi, S.R., Vélez, M.A., Vaira, S. and Perotti, M.C. (2016). Adulteration of Argentinean milk fats with animal fats: Detection by fatty acids analysis and multivariate regression techniques. Food Chemistry, 192, 1025-1032. https://doi.org/10.1016/ j.foodchem.2015.07.107

Riyanta, A.B., Riyanto, S., Lukitaningsih, E. and Rohman, A. (2020). The employment of Fourier transform infrared spectroscopy (FTIR) and chemometrics for analysis of candlenut oil in binary mixture with grape seed oil. Food Research, 4(1), 184-190. https://doi.org/10.26656/fr.2017.4(1).279

Rohman, A., Windarsih, A., Riyanto, S., Sudjadi, Shuhel -Ahmad, S.A., Rosman, A.S. and Yusoff, F.M. (2016). Fourier Transform Infrared Spectroscopy Combined with Multivariate Calibrations for the Authentication of Avocado Oil. International Journal of Food Properties, 19(3), 680-687. https:// doi.org/10.1080/10942912.2015.1039029

Sohng, W., Park, Y., Jang, D., Cha, K., Jung, Y.M. and Chung, H. (2020). Incorporation of two-dimensional correlation analysis into discriminant analysis as a potential tool for improving discrimination accuracy: Near-infrared spectroscopic discrimination of adulterated olive oils. Talanta, 212, 1-9. https:// doi.org/10.1016/j.talanta.2020.120748

Upadhyay, N., Jaiswal, P. and Jha, S.N. (2016). Detection of goat body fat adulteration in pure ghee using ATR-FTIR spectroscopy coupled with chemometric strategy. Journal of Food Science and Technology, 53(10), 3752-3760. https:// doi.org/10.1007/s13197-016-2353-2

Worley, B. and Powers, R. (2013). Multivariate analysis in metabolomics. Current Metabolomics, 1(1), 92107. https://doi.org/10.2174/2213235X130108

Yanty, N.A.M., Marikkar, J.M.N. and Miskandar, M.S. (2012). Comparing the thermo-physical characteristics of lard and selected plant fats. Grasas $y$ Aceites, 63(3), 328-334. https://doi.org/10.3989/ gya. 023712

Yao, Y., Zhao, G., Xiang, J., Zou, X., Jin, Q. and Wang, $X$. (2016). Lipid composition and structural characteristics of bovine, caprine and human milk fat globules. International Dairy Journal, 56, 64-73. https://doi.org/10.1016/j.idairyj.2015.12.013 